\title{
Physical mapping of the mec region of an Australian methicillin-resistant Staphylococcus aureus lineage and a closely related American strain
}

\author{
Donald T. Dubin, ${ }^{1 *}$ Sucheta G. Chikramane, ${ }^{1}$ Barbara Inglis, ${ }^{2}$ Peter R. Matthews ${ }^{2} \dagger$ and \\ PETER R. STEWART ${ }^{2}$ \\ ${ }^{1}$ Department of Molecular Genetics and Microbiology, University of Medicine and Dentistry of New Jersey - Robert Wood \\ Johnson Medical School, Piscataway, NJ 08854, USA \\ 2 Division of Biochemistry and Molecular Biology, Faculty of Science, Australian National University, \\ Canberra ACT 2601, Australia
}

(Received 25 March 1991; revised 29 July 1991; accepted 16 September 1991)

\begin{abstract}
Methicillin-resistant $\left(\mathrm{Mc}^{\mathrm{r}}\right.$ ) staphylococci contain chromosomal DNA that is absent from $\mathbf{M c}^{\mathrm{s}}$ cells. This extra DNA harbours the methicillin resistance determinant mec and often other resistance determinants. The mec region can differ substantially in structure among different isolates. We present studies on the mec region of a group of Staphylococcus aureus isolates prevalent in Australia and London. Southern hybridization analyses of a prototype Australian isolate, ANS46, and an isogenic Mc $\mathrm{c}^{5}$ deletion mutant, ANS62, allowed the physical map of the region to be extended to $55 \mathrm{~kb}$. The DNA corresponding to the deletion, which includes mec and resistance determinants for mercury, cadmium (Cd) and tetracycline, amounted to $41 \mathrm{~kb}$. It was bounded precisely at one end by the macrolides-lincosamides-streptogramin B (MLS)-resistance transposon, Tn554. Near the other end was an element with homology to $\mathrm{Tn} 554, \psi \mathrm{Tn} 554$, which carried the $\mathrm{Cd}^{\mathrm{r}}$ determinant. The mec region of an American Mcr isolate, R35, was found to be virtually the same as that of ANS46, except that it lacked Tn554. Another class of American Mcr isolates, prevalent since 1987, differs markedly from ANS46 in mec region organization. However, this other American class also contains an insertion of Tn554 in the mec region, and the attachment site for this insertion was found to have significant homology to attachment sites for the Tn554 and $\psi$ Tn554 insertions in the mec region of the Australian strain. These results suggest possible roles of Tn554 and Tn554-like elements in the evolutionary variation of the mec region.
\end{abstract}

\section{Introduction}

In Staphylococcus aureus, the structural gene for methicillin resistance, $m e c$, resides in a region of the chromosome that is of considerable interest. The mec region can harbour various resistance determinants in addition to $m e c$, the number, nature and arrangement of which can vary significantly among different isolates (Ubukata $e t$ al., 1989; Matthews et al., 1990; Dubin et al., 1991). mec is part of a DNA insertion of $20 \mathrm{~kb}$ or more that has no allelic counterpart in chromosomes of typical $\mathrm{Mc}^{\mathrm{s}} S$. aureus isolates. This DNA is thought to have arisen by transfer from a different organism (Matthews et al.,

$\dagger$ Present address: Rockefeller University, York Avenue, New York, NY 10021, USA.

Abbreviations: MLS, macrolides-lincosamides-streptogramin B; Sp, spectinomycin; $\triangle \mathrm{ANS} 46 / 62$, the DNA corresponding to that deleted from strain ANS46 yielding ANS62.
1987; Beck et al., 1986; Song et al., 1987; Skinner et al., 1988; Dubin, 1990). In the prototype Australian isolate ANS46, which has been extensively characterized (Matthews et al., 1987, 1990), mec is associated with mer, tet, and cad genes and four copies of the insertion sequence IS257 (Fig. 1).

The staphylococcal transposon Tn554 encodes macrolides-lincosamides-streptogramin B (MLS) and spectinomycin (Sp) resistance (reviewed in Murphy, 1990). Tn554 is relatively site-specific, entering only the primary chromosomal attachment site in laboratory $S$. aureus strain 8325 (Murphy et al., 1981). However, clinical isolates often have secondary chromosomal insertions of Tn554 (Thakker-Varia et al., 1987; Dubin, 1990). A new group of $\mathrm{Mc}^{\mathrm{r}} S$. aureus isolates causing an outbreak in New Jersey in 1987 (the New Jersey group) was found to contain a characteristic secondary insertion designated class 6 (Tillotson et al., 1989). A group of isolates endemic in Australia and England for about 10 


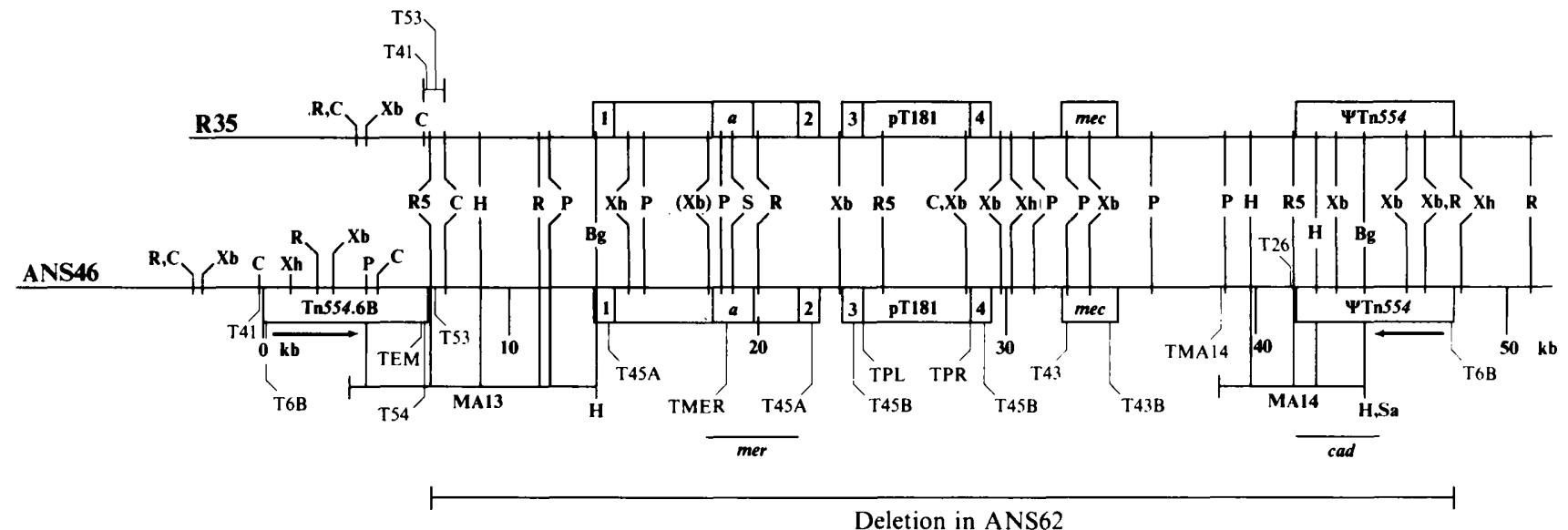

Fig. 1. Maps of the mec regions of Australian strain ANS46 and New Jersey strain R35. All sites for EcoRI (R), PstI (P), SmaI (S), XbaI $(\mathrm{Xb})$, and $\mathrm{XhoI}(\mathrm{Xh})$, and selected sites for BgIII (Bg), ClaI (C), EcoRV (R5) and HindIII (H) are shown. The XbaI site in parentheses was partially resistant to cleavage. IS257 insertions are designated 1-4 (Matthews et al., 1990) and Tn554 insertion 6B is designated Tn554 6B. Orientations of transposase reading frames of $\mathrm{Tn} 554$ and $\psi \mathrm{Tn} 554$ are shown by arrows. Below the ANS46 map we depict cloned fragments MA 3 and MAl 4 with selected restriction sites, and general locations for $\mathrm{Hg}$ and $\mathrm{Cd}$ resistance determinants (Skinner et al., 1988; Matthews et al., 1987, 1990). The location of the mer $A$ gene as inferred from the restriction map of Laddaga et al. (1987) is indicated by $a$. The positions of several oligonucleotide probes (T prefixes) hybridizing with ANS46 DNA are shown. Those from T53 rightwards hybridized similarly with R35 DNA. Above the R35 map is shown the $0.8 \mathrm{~kb}$ ClaI fragment corresponding to unoccupied att 35 . Due to the cloning strategy used, Bg/II sites of chromosomal DNA correspond to HindIII and SalI (Sa) polylinker sites at ends of cloned segments.

years (Pavillard et al., 1982; Cookson \& Phillips, 1988) (the Australondon lineage) was found also to contain a distinctive Tn554 insertion, 6B (Chikramane et al., 1991). Insertions 6 and $6 \mathrm{~B}$ have similar left flanking chromosomal DNA sequences and have been mapped to the mec regions of their respective lineages (Chikramane et al., 1991; Dubin et al., 1991).

Study of the Australondon strains has been facilitated by the availability of an $\mathrm{Mc}^{\mathrm{s}}$ variant, ANS62, of the prototype Australian $\mathrm{Mc}^{\mathrm{r}}$ isolate ANS46. ANS62 was found to have undergone a deletion of at least $35 \mathrm{~kb}$ of DNA ( $\triangle$ ANS46/62) from ANS46 (Matthews et al., 1987). Clones corresponding to this missing DNA were used in mapping a substantial portion of the region (Matthews et al., 1987, 1990; Skinner et al., 1988). The present work extends this map. We show that Tn554 insertion 6B is just beyond the left boundary of $\triangle \mathrm{ANS} 46 / 62$; and that an element resembling Tn554 but encoding $\mathrm{Cd}^{\mathrm{r}}$, designated $\psi \mathrm{Tn} 554$, is at the right end of $\triangle \mathrm{ANS} 46 / 62$. We have also examined a representative strain, R35, of a separate New Jersey Mcr lineage. R35 was found to have a mec region essentially the same as that of the Australondon lineage, but lacking a Tn554 insertion.

\section{Methods}

Bacterial strains and susceptibility determinations. S. aureus strains and pertinent characteristics are summarized in Table 1. Antibiotic susceptibilities were determined by disc diffusion (Barry \& Thorns- berry, 1980). Cd susceptibility was assessed by plating onto $C Y$ agar containing $100 \mu \mathrm{M}-\mathrm{CdCl}_{2}$ (Skinner et al., 1988). $\mathrm{Hg}$ susceptibility was determined with discs containing 20 and $100 \mathrm{nmol} \mathrm{HgCl}_{2}$ (Weiss $e t$ al., 1977).

Plasmid pEM715 was provided by E. Murphy, in S. aureus RN4932 (Thakker-Varia et al., 1987).

DNA methods. Total cellular DNA was prepared after lysing cells with lysozyme, lysostaphin and SDS (Chikramane et al., 1991). Southern blots were prepared as before (Tillotson et al., 1989). In most cases $0.7 \%$ agarose gels were used, with size standards consisting of HindIII fragments of bacteriophage $\lambda$, end-labelled by filling in with the Klenow fragment of Escherichia coli DNA polymerase. To analyse small fragments $1.2 \%$ or $2 \%(w / v)$ gels were used, with a $11 \mathrm{~kb}$ ladder' (BRL/Life Technologies), similarly labelled, as standard. Filters were hybridized, and washed, as described previously (Berent et al., 1985; Chikramane et al., 1991).

PCR amplification was performed using Amplitaq (Cetus Corp), following the supplier's recommended protocol.

DNA sequencing was performed by a dideoxynucleotide procedure (Sanger et al., 1977).

Nomenclature of Tn554 insertions and their attachment sites. Tn554 insertions in staphylococci have been classified on the basis of restriction pattern of adjacent chromosomal DNA (Tillotson et al., 1989). The most common insertion in $S$. aureus is designated the primary insertion or insertion 1. Commonly found secondary insertions have been numbered 2-8 (Tillotson et al., 1989). Appended letters (e.g., insertion 2B) generally denote restriction site polymorphisms. For insertion 6B, the B reflects a more marked difference from insertion 6 , namely a different right adjacent chromosomal arm.

The attachment (att) site for the primary insertion is designated att554 after Tn554 (see Murphy, 1990). att sites for secondary insertions are named after prototype strains, e.g. att 155 corresponds to insertion 6 in strain R155 and att46 corresponds to insertion 6B in strain ANS46. att 35 , in which no Tn 554 insertion has been detected, refers to the locus 
Table 1. Bacterial strains

\begin{tabular}{|c|c|c|c|c|c|c|c|}
\hline \multirow[b]{2}{*}{ Strain } & \multicolumn{6}{|c|}{$\begin{array}{l}\text { Antimicrobial agent } \\
\text { susceptibilities* }\end{array}$} & \multirow[b]{2}{*}{ Description } \\
\hline & Sp & MLS & $\mathrm{Hg}$ & $\mathrm{Tc}$ & Mc & $\mathrm{Cd}$ & \\
\hline WJ137 & $\mathbf{R}$ & $\mathbf{R}$ & $\mathbf{S}$ & $\mathbf{S}$ & $\mathbf{S}$ & $\mathbf{R}$ & $\begin{array}{l}\text { New Jersey } \mathbf{M c}^{\mathrm{s}} \text { isolate with } \mathrm{Tn} 554 \\
\text { insertions } 1 \text { and } 2 \text { (Thakker-Varia } \\
\text { et al., 1987). }\end{array}$ \\
\hline R155 & $\mathbf{R}$ & $\mathbf{R}$ & $\mathbf{S}$ & $S$ & $\mathbf{R}$ & $S$ & $\begin{array}{l}\text { New Jersey Mcr outbreak isolate } \\
\text { with Tn554 insertions IB (similar } \\
\text { to 1) and } 6 \text { (Tillotson et al., 1989; } \\
\text { Chikramane et al., 1991). }\end{array}$ \\
\hline ANS46 & $\mathbf{R}$ & $\mathbf{R}$ & $\mathbf{R}$ & $\mathbf{R}$ & $\mathbf{R}$ & $\mathbf{R}$ & $\begin{array}{l}\text { Australian Mcr isolate (Matthews et } \\
\text { al., 1987) containing Tn554 insertions } \\
\text { 1, 2B (similar to 2), and 6B } \\
\text { (Chikramane } \text { et al., 1991). }\end{array}$ \\
\hline ANS62 & $\mathbf{R}$ & $\mathbf{R}$ & $\mathbf{S}$ & $(\mathrm{R}) \dagger$ & $S$ & $S$ & $\begin{array}{l}\text { Mc deletant of ANS46 (Matthews et } \\
\text { al., 1987) with Tn554 insertions 1, }\end{array}$ \\
\hline R35 & $\mathbf{S}$ & $R_{\ddagger}^{+}$ & $\mathbf{R}$ & $\mathbf{R}$ & $\mathbf{R}$ & $\mathbf{R}$ & $\begin{array}{l}\text { 2B, and 6B' (Chikramane et al., 1991). } \\
1987 \text { New Jersey } \mathrm{Mc}^{r} \text { isolate lacking } \\
\text { Tn554 (Tillotson et al., 1989). }\end{array}$ \\
\hline
\end{tabular}

- Abbreviations: Sp, spectinomycin; MLS, macrolides-lincosamides-streptogramin B; Hg, mercury; Tc, tetracycline; Mc, methicillin; $\mathrm{Cd}$, cadmium.

$\dagger$ Decreased $\mathrm{Tc}^{r}$ due to the absence of tetA, but presence of another $\mathrm{Tc}^{r}$ determinant.

$\ddagger$ MLS due to ermC in the plasmid pNE131.

in strain R35 that is homologous to att46. When an att site is occupied, DNA to the left (or right) of the transposon is referred to as the left (or right) att site arm. This terminology is extended to unoccupied att sites by reference to the position of the predicted transposon-mediated cleavage of the site.

The designations insertion $6 \mathrm{~B}^{\prime}$ and att46 for ANS62 are special cases. As explained in experiments now to be described, these are the same as insertion $6 \mathrm{~B}$ and att46 except for the fact that $\triangle \mathrm{ANS} 46 / 62$ abuts the insertion.

The term pseudotransposon for $\psi \mathrm{Tn} 554$ reflects the fact that a portion of this element (about half) was found to be homologous to Tn554, while the rest lacked homology. Further, DNA adjacent to the left end of $\psi \operatorname{Tn} 554$ (orientation as in Fig. 1) proved to be homologous to DNA adjacent to Tn554 insertion 6 of strain R155.

\section{Results}

General organization of the Australondon mec region, mapping rationale, and comparison to New Jersey strain $R 35$

Fig. 1 shows a physical map covering $55 \mathrm{~kb}$ of the mec region of the ANS46 chromosome. DNA in the central portion of this map amounting to approximately $35 \mathrm{~kb}$ has been characterized in detail (Matthews et al., 1990; Inglis et al., 1990). This $35 \mathrm{~kb}$ stretch extends between the regions of the leftmost and rightmost cloned fragments from $\triangle \mathrm{ANS} 46 / 62$, clones MA13 and MA14. In addition to mec, this $35 \mathrm{~kb}$ region contains an $\mathrm{Hg}$ resistance operon and an integrated copy of the $\mathrm{Tc}^{\mathrm{r}}$ plasmid pT181, both flanked by copies of the insertion sequence IS257 (Skinner et al., 1988; Matthews et al., 1990).

The clone MA13 includes part of Tn554 insertion 6B (Chikramane et al., 1991). As shown below, MA14 includes part of what we refer to as the pseudotransposon $\psi \operatorname{Tn} 554$, which hybridized with some of the probes derived from Tn554. Thus, Tn554-related probes helped refine the map of mec-associated DNA covered by MA13 and MA14, and permitted extension of the map beyond the cloned segments. These probes are summarized in Figs 1 and 2, and Table 2.

Fig. 3 shows Southern hybridization patterns illustrating relationships between DNA contained in clones MA13 and MA14, Tn554 insertion 6B, and the $\psi \operatorname{Tn} 554$ insertion. We ran, in parallel, samples of a HindIII plus PstI digest of an MAl3-containing plasmid (lane 1), a HindIII plus PstI digest of chromosomal DNA from an Australondon strain (lane 2), and a HindIII digest of an MA14-containing plasmid (lane 3). (a) shows ethidium bromide-stained bands; patterns are as expected from earlier work (see Fig. 3 legend and Matthews et al., 1990).

Fig. 3(b) shows a blot hybridized with oligonucleotide TEM. This probe is specific for Tn554, and hybridizes with right junction fragments of the three Tn554 insertions of the Australondon chromosome (Chikramane et al., 1991). The $4.6 \mathrm{~kb}$ Pst $\mathrm{I} /$ HindIII band from Tn554 insertion 6B comigrates with a band from MA13, showing that MA13 includes the right junction of Tn554 insertion 6B (Fig. 1). MA14 did not hybridize with the TEM probe (Fig. 3), nor did it hybridize with 


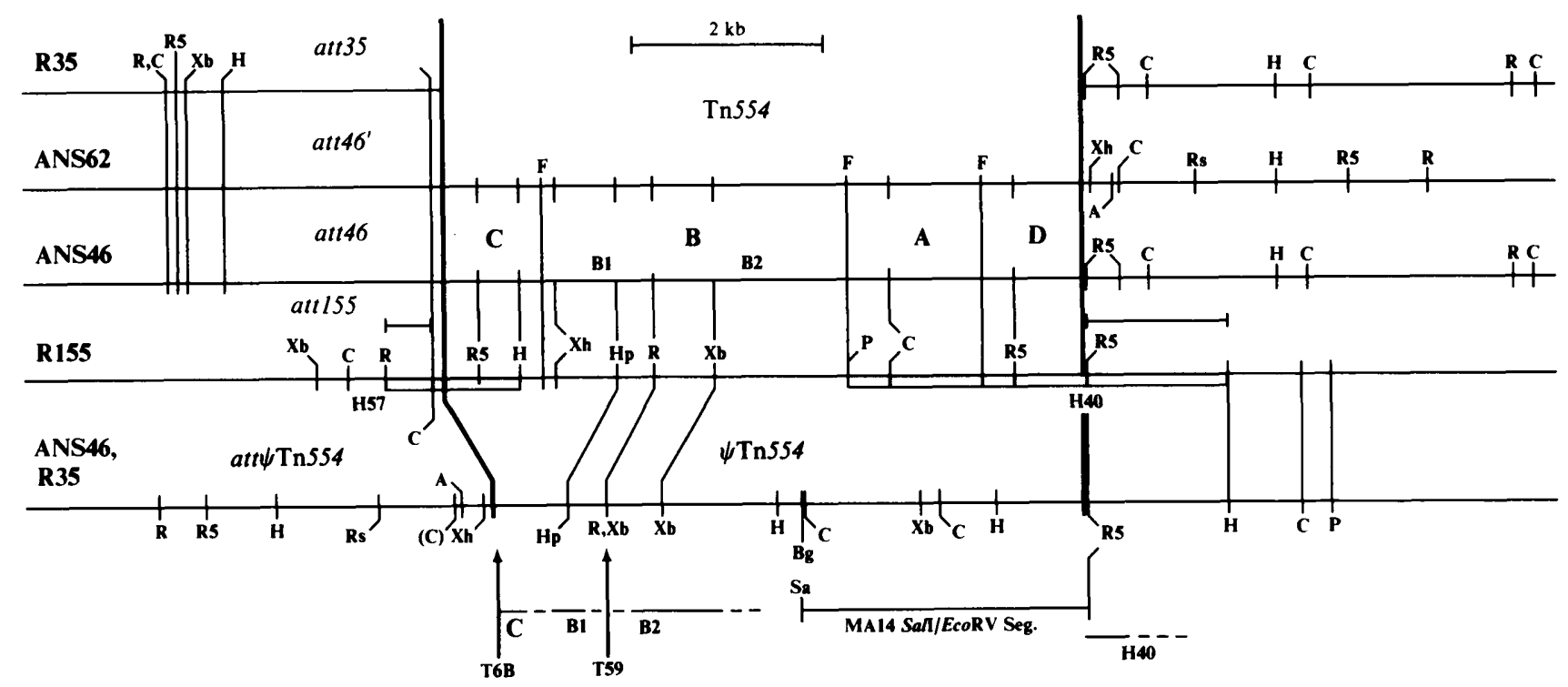

Fig. 2. Restriction maps of Tn554-related portions of the mec region. Maps of the $\psi$ Tn 554 insertion of ANS46 and R35 (lowest extended line), Tn554 insertion 6 of R155, insertion 6B of ANS46, insertion 6B' of ANS62, and the region of R35 corresponding to insertion 6B are shown. These are denoted by strain and att site designations. Restriction sites within $\approx 5 \mathrm{~kb}$ of junctions are shown for $\mathrm{ClaI}(\mathrm{C})$, EcoRI (R), EcoRV (R5), HindIII (H), PstI (P), XbaI (Xb) and XhoI (Xh), and selected sites are shown for BglII (Bg), HpaI (Hp), RsaI (Rs) and $A l u \mathrm{I}$ (A). In addition, we show Fnu4HI (F) sites bounding Tn554 segments of plasmid pEM9715 (Thakker-Varia et al., 1987) used as probes. The orientation of $\psi \mathrm{Tn} 554$ is reversed relative to that shown in Fig. 1. The ClaI site in parentheses is partially resistant to digestion in R35. The boundaries of Tn554 and $\psi \operatorname{Tn} 554$ are shown as heavy vertical lines. Cloned Tn 554 fragments (A, B, B1, B2, C, and D) are shown by bold letters. Cloned junction fragments from insertion 6 (H57, H40; Tillotson et al., 1989) are shown as shaded rectangles. Bars above these rectangles define the EcoRI/ClaI and EcoRV/HindIII fragments used as att arm-specific probes. Below the map of the $\psi \operatorname{Tn} 554$ insertion, we indicate regions of this insertion that are homologous to Tn 554 fragments $\mathrm{C}$, B1 and B2, to two Tn554related oligonucleotides, to the Sal/EcoRI fragment of MA14, and to H40. Dashed lines indicate that the precise extent of homologous sequence is not known. For R35 we interrupt the map over the region presumed to correspond to the (absent) Tn554 insertion.

Tn554 cloned fragment probes A-C (Fig. 2 and Table 2) (data not presented). Thus, this clone must lack homology to $\operatorname{Tn} 554$, and the portion of $\psi \operatorname{Tn} 554$ included in MA14 (the left half as drawn in Fig. 1, the right half as drawn in Fig. 2) also lacks homology to Tn554.

Fig. $3 c$ presents results with an oligonucleotide probe, T26, based on the sequence of the right flanking chromosomal DNA of Tn554 insertion 6 (i.e. the right arm of attachment site att 155 as it occurs in the 1987 New Jersey outbreak group (Tillotson et al., 1989). T26 failed to hybridize with MA13 (lane 1), confirming the finding (Chikramane et al., 1991) that the right flanking chromosomal DNA of insertion 6B (i.e., the right arm of the attachment site in ANS46 referred to as att46) differs from that of att 155. However, oligonucleotide T26 did hybridize with an MA14 HindIII fragment of approximately $2.4 \mathrm{~kb}$ (lane 3 ). A similar fragment had previously been found in New Jersey strain R35 (Tillotson et al., 1989). The $2.4 \mathrm{~kb}$ HindIII fragments from ANS46 and R35 also hybridized with an EcoRV/HindIII fragment of clone $\mathrm{H} 40$ specific for the right adjacent chromosomal DNA of insertion 6 of strain R155 (Table 2 and Fig. 2). This HindIII fragment was absent from ANS62 (data not shown). Thus, the mec regions of ANS46 and R35 carry a substantial length of DNA similar to the right arm of att155. Sequence analysis (S. G. Chikramane \& D. T. Dubin, unpublished results) has shown that both the T26 and $\mathrm{H} 40$ probes hybridize to DNA that abuts $\psi \mathrm{Tn} 554$ (on the left as drawn in Fig. 1 and on the right as drawn in Fig. 2). Thus this DNA can be considered to be an arm of a putative att site, 'att $\psi \operatorname{Tn} 554$ ', which is partially homologous to att 155. The $2.4 \mathrm{~kb}$ HindIII fragment of MA14 corresponds to a junction fragment of $\psi \operatorname{Tn} 554$ (approx. coordinates 39.5 to $42 \mathrm{~kb}$ in Fig. 1).

To further explore the relationship between R35 and ANS46 we used a series of probes spaced along the ANS46 map in Southern hybridizations with DNA digested with the nine endonucleases cited in the legend to Fig. 1. Several of these probes are oligonucleotides corresponding to sequence within $\triangle \mathrm{ANS} 46 / 62$ (Fig. 1 and Table 2), as follows: T45A and T45B are specific for the left and right pair of IS257 elements, respectively (Matthews et al., 1990); TMER is based on the sequence of the pI258 merA gene (Laddaga et al., 1987); TPL and TPR are specific for the left and right IS257-pT181 junctions of ANS46 (Matthews et al., 1990); T43 and 
Table 2. Probes derived from Tn554 elements used for mapping mec-associated DNA

\begin{tabular}{|c|c|c|c|c|c|}
\hline \multirow[b]{3}{*}{ Probe* } & \multicolumn{5}{|c|}{$\begin{array}{l}\text { Tn554-related elements } \dagger \\
\text { (prototype strain) }\end{array}$} \\
\hline & \multicolumn{3}{|c|}{ Insertion } & \multirow[b]{2}{*}{$\begin{array}{c}\psi \operatorname{Tn} 554 \\
\text { (ANS46, R35) }\end{array}$} & \multirow[b]{2}{*}{$\begin{array}{l}a t t 35 \\
\text { (R35) }\end{array}$} \\
\hline & $\begin{array}{l}6 \\
(\mathrm{R} 155)\end{array}$ & $\begin{array}{l}\text { 6B } \\
\text { (ANS46) }\end{array}$ & $\begin{array}{c}\text { 6B' } \\
\text { (ANS62) }\end{array}$ & & \\
\hline \multicolumn{6}{|l|}{ Left att 155} \\
\hline T41 & + & + & + & - & + \\
\hline H57 EcoRI/ClaI segment & + & + & + & - & + \\
\hline \multicolumn{6}{|l|}{ Tn554 (internal) } \\
\hline T6B (left end) & + & + & + & + & - \\
\hline Fragment $\mathrm{C}$ & + & + & + & + & - \\
\hline Fragment B & + & + & + & + & - \\
\hline Fragment $\mathrm{A}$ & + & + & + & - & - \\
\hline Fragment D & + & + & + & - & - \\
\hline TEM (right penultimate) & + & + & + & - & - \\
\hline T54 (Australondon right end) & - & + & + & - & - \\
\hline \multicolumn{6}{|l|}{$\psi \operatorname{Tn} 554$} \\
\hline T59 & - & - & - & + & - \\
\hline MAl4 EcoRV/SalI segment & - & - & - & + & - \\
\hline \multicolumn{6}{|l|}{ Right att 155} \\
\hline T26 & + & - & - & + & - \\
\hline H40 EcoR V/HindIII segment & + & - & - & + & - \\
\hline \multicolumn{6}{|l|}{ Right att 46} \\
\hline T53 & - & + & - & - & + \\
\hline MA13 HindIII/EcoRI seg- & & & & & \\
\hline ment $t$ & - & + & - & - & + \\
\hline
\end{tabular}

* Oligonucleotide probes (T prefixes) have been described previously (Chikramane et al., 1991; see also Fig. 1) except for T59. This is the reverse complement of GAATTCGTCTAGAGC, which corresponds to Tn554 residues 2212 to 2229 (Murphy et al., 1985), except that the underlined residue, which is a C in Tn554, was converted to a T to create an XbaI site (see Results). DNA fragment probes are shown in Figs 1 and 2.

$+\operatorname{Tn} 554$ and $\psi \operatorname{Tn} 554$ insertions include adjacent att arms. Hybridization (+) or lack of it $(-)$ of the insertions and of att35 to the listed probes is shown.

$\ddagger$ Around the $10 \mathrm{~kb}$ coordinate on the map of Fig. 1 .

T43B are from the mec sequence (Song et al., 1987); and TMA14 is based on sequencing (S. G. Chikramane \& D. T. Dubin, unpublished results) of MA14. All of these probes hybridized strongly with ANS46 and R35 and yielded the same Southern hybridization patterns with both strains (data not shown).

Southern hybridization using Tn554 insertion-related probes: extension of the map through and beyond MAI3 and MAl4

The presence in ANS46 of two other copies of Tn554 (the primary insertion and a secondary insertion, 2B), in addition to Tn554 6B and $\psi \mathrm{Tn} 554$ (Chikramane et al., 1991), led to complex Southern hybridization patterns with some Tn554-related probes. To facilitate interpretation, in most experiments four strains were processed in parallel with ANS46. ANS62, the Mc ${ }^{\mathrm{s}}$ deletion mutant of ANS46, indicated whether a particular ANS46 band was all or partly within $\triangle \mathrm{ANS} 46 / 62$ and hence could be considered part of the mec region. WJ137, a recent New Jersey $\mathrm{Mc}^{\mathrm{s}}$ isolate, provided markers for $\mathrm{Tn} 554$ insertions 1 and 2B (Thakker-Varia et al., 1987). New Jersey isolate R35 proved especially valuable in that its mec region closely resembled that of ANS46, but it lacked Tn554. Finally, it was of interest to compare New Jersey outbreak prototype strain R155 with an Australondon strain.

As an example, Fig. 4 shows hybridizations of EcoRIdigested DNA. The complexity of patterns obtained for ANS46 with an internal Tn554 probe (B) which spans the single EcoRI site of the transposon is shown in Fig. $4(a)$, lane 5 . The complexity is due to the presence of three $\operatorname{Tn} 554$ insertions, as well as $\psi \operatorname{Tn} 554$. This last element also has a single EcoRI site, and yields two $E c o$ R I fragments ( 4.6 and ca $25 \mathrm{~kb}$ ) which hybridize with probe B. The R35 sample illustrates the utility of this strain. The fragments of R35 that hybridize with internal Tn554-related probes such as probe $B$ can be attributed to the pseudotransposon. Two hybridizing bands from R35 (Fig. 4a, lane 6) migrated with the 4.6 and $\approx 25 \mathrm{~kb}$ 
(a)

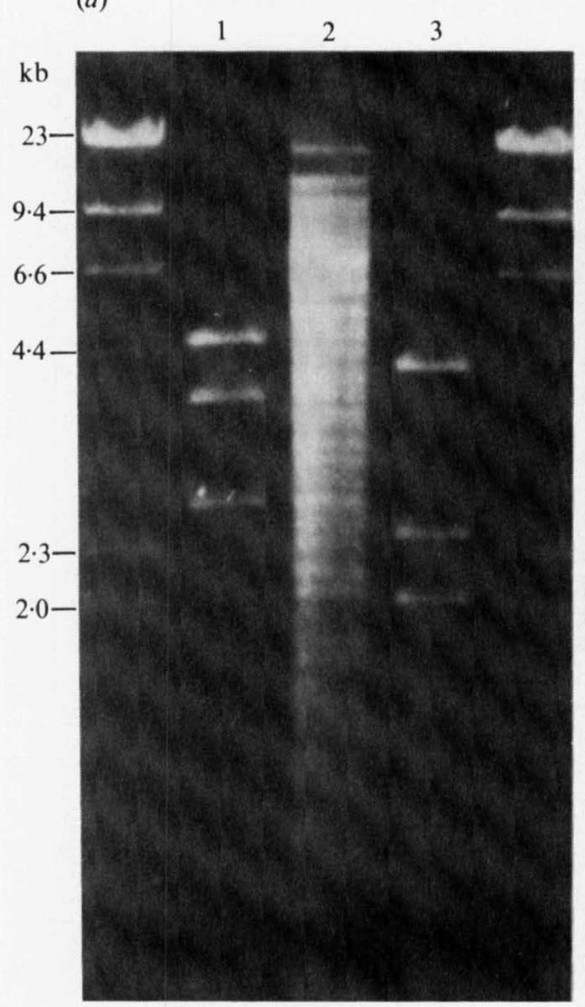

(b) TEM

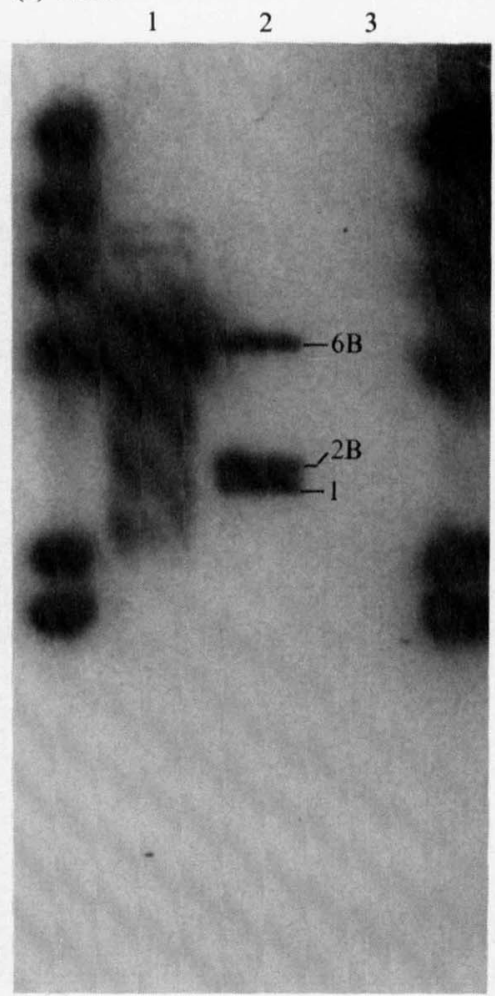

(c) T26

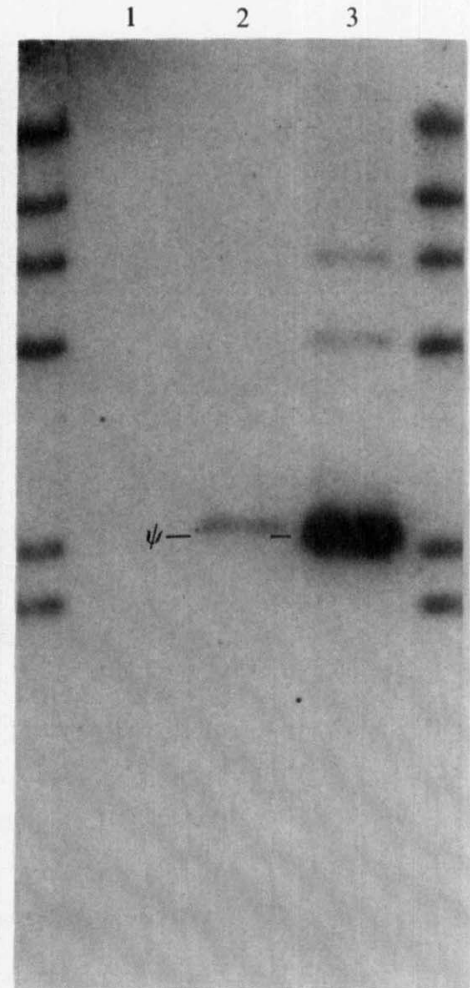

Fig. 3. Southern blot analysis of fragments MA13 and MA14. Bg/lI fragments of ANS46 DNA were cloned into the BamHI site of pGEM-1 (Skinner et al., 1988; Matthews et al., 1990). The end lanes of each panel show markers from a HindIII digest of bacteriophage $\lambda$. (a) shows ethidium bromide-induced fluorescence patterns. Lane l shows a HindIII plus PstI digest of the MAl3-containing plasmid. The major bands are a $3.6 \mathrm{~kb}$ HindIII/Pstl product that includes the $2.9 \mathrm{~kb}$ vector moiety, a $4.6 \mathrm{~kb}$ Pst $/$ HindIII product corresponding to a right junction fragment of insertion $6 \mathrm{~B}$, and a $2.8 \mathrm{~kb}$ HindIII/Pst I product just downstream (the latter two as diagrammed in Fig. 1). Lane 2 shows a HindIII plus PstI digest of DNA from a prototype London isolate of the Australondon lineage (Chikramane et al., 1991). Lane 3 shows a HindIII digest of the MA14-containing plasmid. The major bands are a $4.3 \mathrm{~kb}$ product that includes the vector moiety, and 2.4 and $2.0 \mathrm{~kb}$ products corresponding to those diagrammed in Fig. 1. (b) and (c) represent Southern blots of the separation of $(a)$ and of a parallel separation, hybridized with Tn554-related oligonucleotides TEM $(b)$ or T26 (c) (see Table 2). Designations 1, 2B and 6B, and $\psi$ refer to right junction fragments of $\operatorname{Tn} 554$ insertions or of the $\psi \operatorname{Tn} 554$ insertion, respectively.

bands of ANS46, indicating that the latter bands arose from $\psi \operatorname{Tn} 554$.

ANS62 lacked bands corresponding to the pseudotransposon (Fig. $4 a$, lane 4), showing that this element is part of $\triangle \mathrm{ANS} 46 / 62$. In contrast, ANS62 retained bands corresponding to Tn554 insertion 6B. We designate the 6B equivalent in ANS62 insertion 6 $\mathrm{B}^{\prime}$. The band corresponding to the right $E c o$ RI fragment (6B'R, lane 4) migrated differently from its counterpart in ANS46, reflecting the fact that insertion $6 \mathrm{~B}^{\prime}$ is near the $\triangle \mathrm{ANS} 46 / 62$ boundary (Chikramane et al., 1991).

Fig. 4(b) illustrates the homology between the DNA flanking the left end of insertion $6 \mathrm{~B}$ of the Australondon lineage (i.e. the left arm of att46), and the left arm of att155. Oligonucleotide T41, based on the att155 sequence of strain R155 (Tillotson et al., 1989), recognized
EcoRI fragments in ANS46 DNA (6BL, lane 5) and ANS62 DNA (6B'L, lane 4), as well, of course, as a fragment in R155 DNA (6L, lane 3).

The comigration of $6 \mathrm{~B}^{\prime} \mathrm{L}$ with $6 \mathrm{BL}$ (Fig. $4 b$, lanes 4 and 5) is in accord with our previous mapping (Chikramane et al., 1991), and reflects the fact that the deletion does not extend leftwards into Tn554 insertion $6 \mathrm{~B}$. The marked difference in migration between the $6 \mathrm{~B}^{\prime} \mathrm{L} / 6 \mathrm{BL}$ bands, and that from $\mathrm{R} 155(6 \mathrm{~L})$, reflects the fact that sequences near att46 and att 155 become divergent beginning a few hundred residues leftwards of the insertion sites. The $\approx 7 \mathrm{~kb}$ band generated in $\mathrm{R} 35$ DNA by probe T41 (Fig. $4 b$, lane 6) indicates the presence in this strain of DNA homologous to left arms of att 155 and att46, but the band size differs from those of the other strains (lanes 3,4 and 5) because R35 lacks 
(a) Seg. B

(b) $\mathrm{T} 41$

(c) pT181
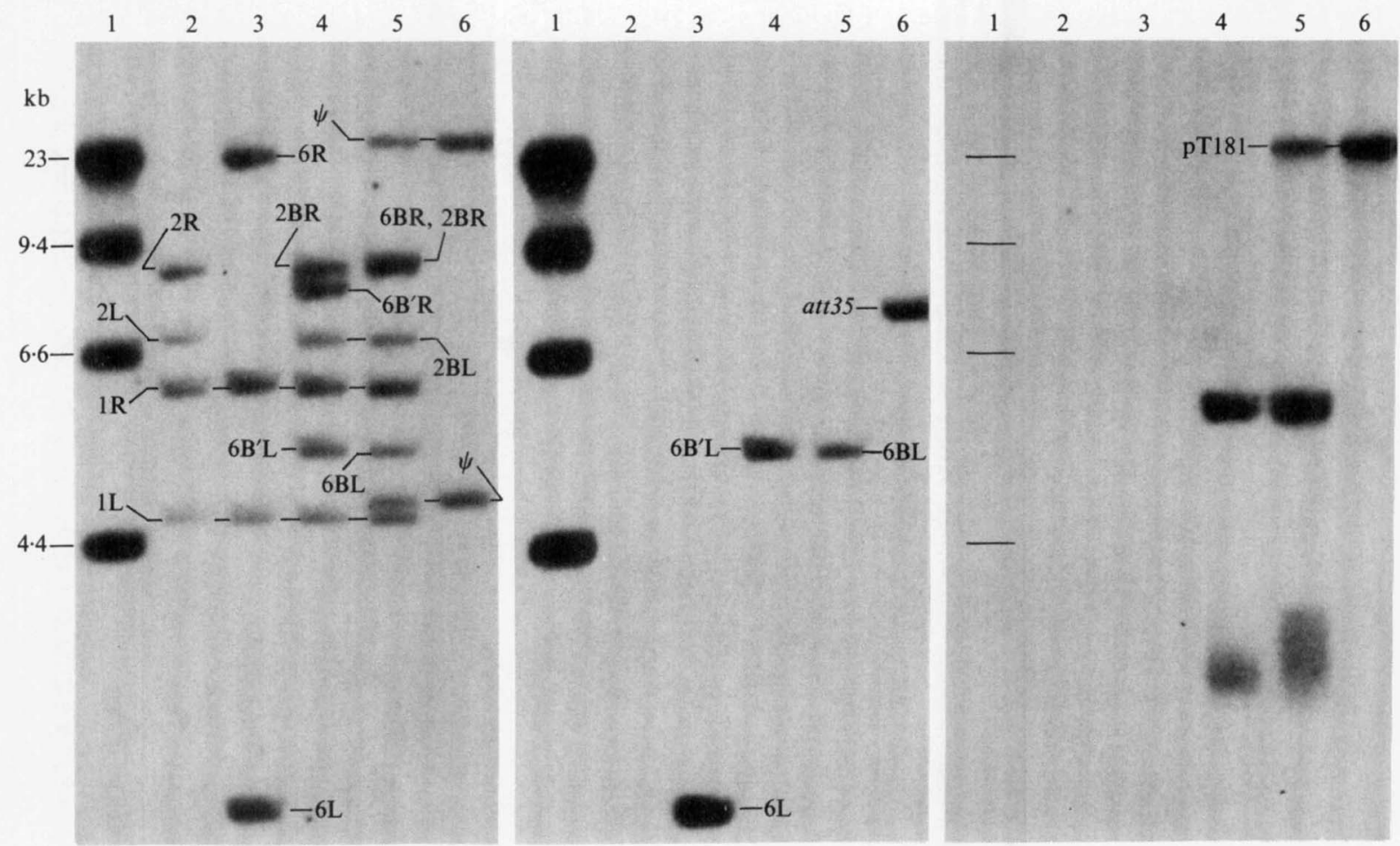

Fig. 4. Southern Blot analysis of EcoRI digests. A blot was hybridized sequentially with Tn554 segment B (a), oligonucleotide T4l (b) and a $2.4 \mathrm{~kb}$ pT 181 probe [equivalent to residues 3130-4437/0-1081 in the circular map of Khan \& Novick (1983)] (c). Markers (lane 1) are as for Fig. 3; their positions are drawn in for $(c)$ as the marker ${ }^{32} \mathrm{P}$ had decayed by the time of this hybridization. Lanes 2-6 correspond to strains WJ137, R155, ANS62, ANS46, and R35, respectively (Table 1). Bands are designated according to their element of origin, $\mathbf{R}$ and $\mathrm{L}$ specifying whether right or left junction fragment, and $\psi$ specifying $\psi \mathrm{Tn} 554$.

Tn554 insertions. This R35 band corresponds to a locus similar to att46; we designate the locus att35 and discuss it in greater detail in connection with Fig. 5.

Fig. 4(c) shows the same blot hybridized to a probe containing plasmid pT181 DNA. This probe hybridized to large fragments in ANS46 and R35 DNA (pT181, lanes 5 and 6 ). The pT181-hybridizing bands proved to be the same EcoRI fragment as hybridized to Tn554related probes $(a)$. This was shown by using the array of probes described above. The large EcoRI fragment of ANS46 and R35 thus contains the integrated copy of pT181, mec, and most of $\psi \operatorname{Tn} 554$ (Fig. 1). The faster migrating bands in ANS62 and ANS46 (Fig. 4c, lanes 4 and 5) are probably due to the presence of a $\mathrm{Cm}^{\mathrm{r}}$ plasmid resembling pSK2 (Lyon \& Skurray, 1987) that contains replication DNA homologous to that of pT181 (Projan et al., 1985).

The experiment of Fig. 5 shows ClaI digests probed to illustrate some properties of left ends (orientation as in Fig. 2) of Tn554-related elements in the mec region, and of the left arms of corresponding attachment sites. A filter was hybridized with probe T6B $(a)$, an oligonucleotide based on the left end of Tn554 and which also recognizes $\psi \operatorname{Tn} 554$ (Table 2); and then $(b)$ with the $0.5 \mathrm{~kb} \mathrm{EcoRI} / \mathrm{ClaI}$ fragment of $\mathrm{H} 57$ from the New Jersey strain R155, which contains only sequence to the left of the att 155 insertion site (Fig. 2). A similar filter was hybridized with the entire $1.4 \mathrm{~kb}$ EcoRI/HindIII H57 fragment illustrated in Fig. $2(c)$. This last probe recognized all the bands shown in Fig. 5(a) and $(b)$, but also hybridized to a $0.8 \mathrm{~kb}$ fragment in R35 (Fig. $5 c$, lane 6 ). This agrees with the previous conclusion that the left end of the mapped region of R35 is similar to that of ANS46, except that it lacks a Tn554 insertion. The absence of the insertion would bring the ClaI site of the right arm of the putative att 35 site to within $0.8 \mathrm{~kb}$ of the ClaI site of the left arm (see Fig. 1). The resulting ClaI fragment would hybridize with the $1.4 \mathrm{~kb} \mathrm{H} 57$ fragment but not the $0.5 \mathrm{~kb} E c o \mathrm{RI} / \mathrm{ClaI}$ fragment derived from it, or with oligonucleotide T6B. Thus, R35 appears to contain an unoccupied Tn554 att site.

Verification of this inference was provided by a 


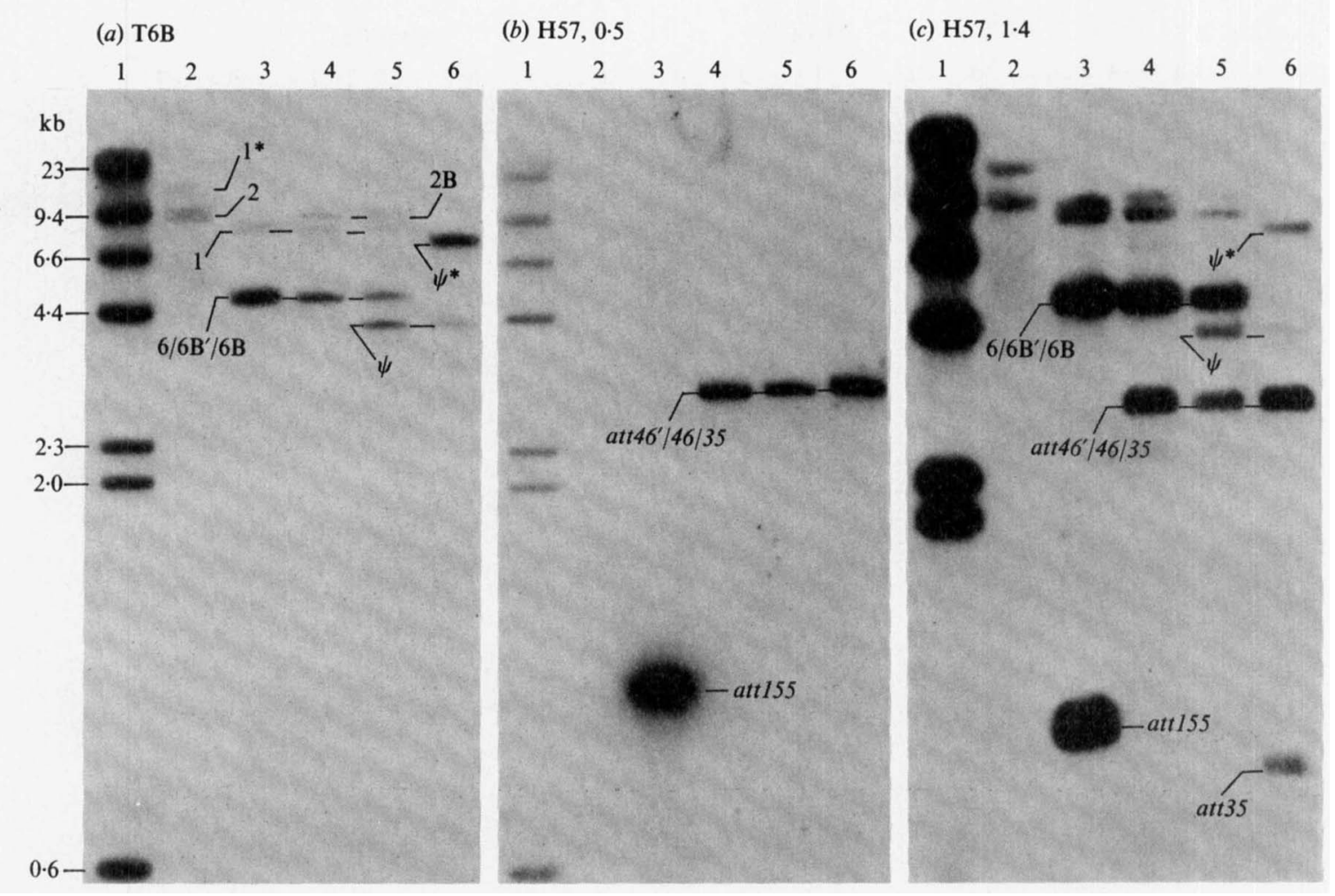

Fig. 5. Southern blot analysis of ClaI digests. For $(a)$ and $(b)$, a blot was hybridized sequentially with oligonucleotide T6B and the $0.5 \mathrm{~kb}$ EcoRI/ClaI fragment of cloned insertion 6 left junction fragment H57 (Fig. 2). A parallel blot was hybridized with the entire $1.4 \mathrm{~kb} \mathrm{H} 57$ fragment $(c)$. Lanes are as for Fig. 4, and bands are identified as for that figure (all being left as drawn in Fig. 2), with the following elaborations: $1^{*}$ designates a restriction fragment length polymorph of the primary insertion of $\mathrm{WJ} 137 ; \psi^{*}$ designates a band arising due to partial resistance of the left-adjacent ClaI site (Fig. 2) of the R35 pseudotransposon insertion; and att designations are applied to bands containing solely attachment site arm moieties.

Southern blot of a ClaI/EcoRV digest of R35 DNA, probed with att155-specific oligonucleotide T41. This probe should hybridize with $a \approx 130 \mathrm{bp}$ fragment from att35. A ClaI cleavage point occurs 113 residues to the left of the putative att 35 cleavage site (as determined for att 155; see Tillotson et al., 1989) and an EcoRV site occurs 19 residues to the right (as determined for att46; Chikramane et al., 1991). Such a fragment was observed, but hybridization of R35 blots with an oligonucleotide, GTGGGGATATAACCCC, that should recognize att46 (see Chikramane et al., 1991) yielded faint bands, suggesting that att35 and att 46 are similar but not identical.

All hybridizing chromosomal segments in Fig. 5(b) correspond to attachment site arm (as opposed to transposon) sequences. The designation att $46^{\prime}$ refers to the hypothetical attachment site of ANS62 insertion 6 $\mathrm{B}^{\prime}$, the right arm of which is quite different from the right arm of att46 (i.e. the right adjacent chromosomal DNA of insertion 6B of ANS46). The results of Fig. 5(b) show that the similarity between the left arm of att 155 and the left arms of att46, att46' and att35 extend substantially beyond their shared ClaI sites. All hybridized with the $0.5 \mathrm{~kb} \mathrm{EcoRI/ClaI}$ fragment of strain R155 clone H57 (Fig. 2).

Fig. 5 demonstrates the only difference noted between the R35 and ANS46 mec regions besides those related to insertion 6B. The ClaI site adjacent to the $\psi \operatorname{Tn} 554$ element in R35 (but not that in ANS46) was partially resistant to digestion (Fig. $5 a$ and $c$, lane 6). This resistance was unaffected by prolonging the digestion time or by increasing the concentration of enzyme. The ClaI site in question may be methylatable. Perhaps in R35 it is partially methylated while in ANS46 it is unmethylated.

\section{Hybridization properties of $\psi \operatorname{Tn} 554$}

Fig. 2 presents maps of Tn 554 insertions 6 of R155, 6B of strain ANS46, and $6 B^{\prime}$ of ANS62, and the analogous chromosomal region of strain $\mathrm{R} 35$. These are compared to the $\psi \operatorname{Tn} 554$ insertion of ANS46 and R35. The $\psi \operatorname{Tn} 554$ 


\title{
Table 3. Hybridization analysis of the left end of the ANS46/ANS62 deletion
}

\begin{abstract}
Oligonucleotide probes correspond to the right chromosomal junction of ANS46 Tn554 insertion 6B. A slash precedes the chromosomal sequence. The three chromosomal nucleotides adjacent to the right ends of insertions 1, 2B and 6B are shown beneath the corresponding headings. All the listed oligonucleotides have a $T_{\mathrm{D}}\left(\right.$ Berent $e t$ al., 1985) of $48^{\circ} \mathrm{C}$. The hybridization temperature was held at 45 $\pm 0.5{ }^{\circ} \mathrm{C} .(+)$ indicates the presence of a band at least $50 \%$ the intensity of insertion $6 \mathrm{~B}$ bands and $(-)$ indicates no band or a band of less than $10 \%$ the intensity of insertion $6 \mathrm{~B}$ bands, determined by Southern blot hybridizations of HindIII plus PstI digests.
\end{abstract}

\begin{tabular}{|c|c|c|c|c|}
\hline \multirow[b]{2}{*}{ Probe } & \multicolumn{4}{|c|}{ Insertion } \\
\hline & $\stackrel{1}{1}$ & $\begin{array}{c}2 \mathrm{~B} \\
(/ \mathrm{CAA})\end{array}$ & $\begin{array}{c}\text { 6B } \\
(/ A C C)\end{array}$ & 6B' \\
\hline T56 TACTCTTGATAATACATC/A & + & + & + & + \\
\hline T57 CTCTTGATAATACATC/AC & + & - & + & - \\
\hline T58 TCTTGATAATACATC/ACC & + & - & + & - \\
\hline
\end{tabular}

insertion is shown in opposite orientation to that of Fig. 1 , to illustrate the similarity between the pseudotransposon and Tn554. In particular, the spacing between the internal HpaI, EcoRI and XbaI sites of Tn554 was indistinguishable from that of corresponding sites in $\psi \operatorname{Tn} 554$. However, there was a discrete difference between these regions of pseudotransposon and transposon, namely, the second $\psi \operatorname{Tn} 554 X b a I$ site apparently coincident with the EcoRI site. Examination of the sequence of Tn554 (Murphy et al., 1985) revealed the string CCTAGA just to the right of the EcoRI site. We tested the idea that the corresponding sequence in $\psi$ Tn 554 was TCTAGA (the $X b a I$ recognition sequence) using oligonucleotide T59 (Table 2). T59 hybridized with $\psi \mathrm{Tn} 554$ (data not shown), implying that the EcoRI site of $\psi \mathrm{Tn} 554$ does correspond to that of Tn554. Also, internal fragments of $\psi \operatorname{Tn} 554$ hybridized to 1.2 and $2 \mathrm{~kb}$ internal Fnu4HI/EcoRI fragments B1 and B2 of Tn554 (Fig. 2) as follows: $\psi \mathrm{Tn} 554$ fragments leftwards of the $E c o \mathrm{RI} / \mathrm{XbaI}$ locus hybridized with probe B1 but not B2, while fragments to the right of this reference point hybridized with probe $\mathrm{B} 2$ but not $\mathrm{B} 1$.

The relationship between $\operatorname{Tn} 554$ and $\psi \operatorname{Tn} 554$ was examined with other probes summarized in Table 2 and Fig. 2. There was extensive sequence similarity between the left $2-3 \mathrm{~kb}$ of $\psi \operatorname{Tn} 554$ and the corresponding part of Tn554 (Fig. 2). No homology was detected between the right portions of the two elements.

\section{Left boundary of the ANS46/ANS62 deletion}

It was inferred from earlier results (Chikramane et al., 1991) that the left boundary of $\triangle A N S 46 / 62$ was within 21 residues of the right end of Tn 554 insertion $6 \mathrm{~B}$. This was based on the facts that insertions 6B of ANS46 and 6B' of ANS62 both hybridize with the right transposonterminal oligonucleotide T54 (Table 2), and that ANS62 lacks an EcoRV site that occurs at residues 16-21 rightwards of ANS46 insertion 6B (Fig. 2 and Chikramane et al., 1991). To localize more precisely the left boundary of the deletion, DNA from ANS46 and ANS62 was hybridized with a set of overlapping oligonucleotides corresponding to the right transposon-chromosome junction of insertion 6B (Table 3). A single $3^{\prime}$ terminal mismatch did not prevent hybridization (see the T56 insertion $2 \mathrm{~B}$ result), but two $3^{\prime}$ terminal mismatches did (T57 insertion 2B). The results for insertion 6B' of ANS62 indicated that the chromosomal sequence directly to the right of the transposon differs from the corresponding sequence for insertion $6 \mathrm{~B}$ at the first residue beyond the transposon. We infer that the left boundary of the deletion begins precisely at the end of the Tn554 sequence of insertion 6B.

\section{Right boundary of the ANS46/ANS62 deletion}

The location of the right boundary of $\triangle \mathrm{ANS} 46 / 62$ was studied with oligonucleotide T6B, which corresponds to the left end of $\psi \mathrm{Tn} 554$ (Fig. 2). To map more precisely the site of hybridization of this oligonucleotide, PCR was use to amplify the DNA between T6B and oligonucleotide T59 (Fig. 2). Major discrete products running at $\approx 1.2 \mathrm{~kb}$ resulted when R35 or ANS46 DNA was used as template (Fig. $6 a$, lanes $1-4$ ). The $\approx 2 \cdot 2 \mathrm{~kb}$ PCR product from ANS46 DNA (Fig. $6 a$, lane 2) probably arises from false priming by T59 in the region of the EcoRI site of $\operatorname{Tn} 554$. The corresponding region of $\mathrm{Tn} 554$, but not $\psi \mathrm{Tn} 554$, contains a HindIII site (Fig. 2), and the $\approx 2 \cdot 2 \mathrm{~kb}$ product was virtually undetectable when ANS46 template DNA was treated with $H$ indIII prior to amplification (Fig. 6a, lane 1). The PCR product from the pseudotransposon was $\approx 0.1 \mathrm{~kb}$ smaller than the $X h o \mathrm{I} /$ $X b a I$ junction fragment, placing the left end of $\psi \mathrm{Tn} 554$ $\approx 0.1 \mathrm{~kb}$ from the $X$ hol site (Fig. 2). More precise values 
(a)

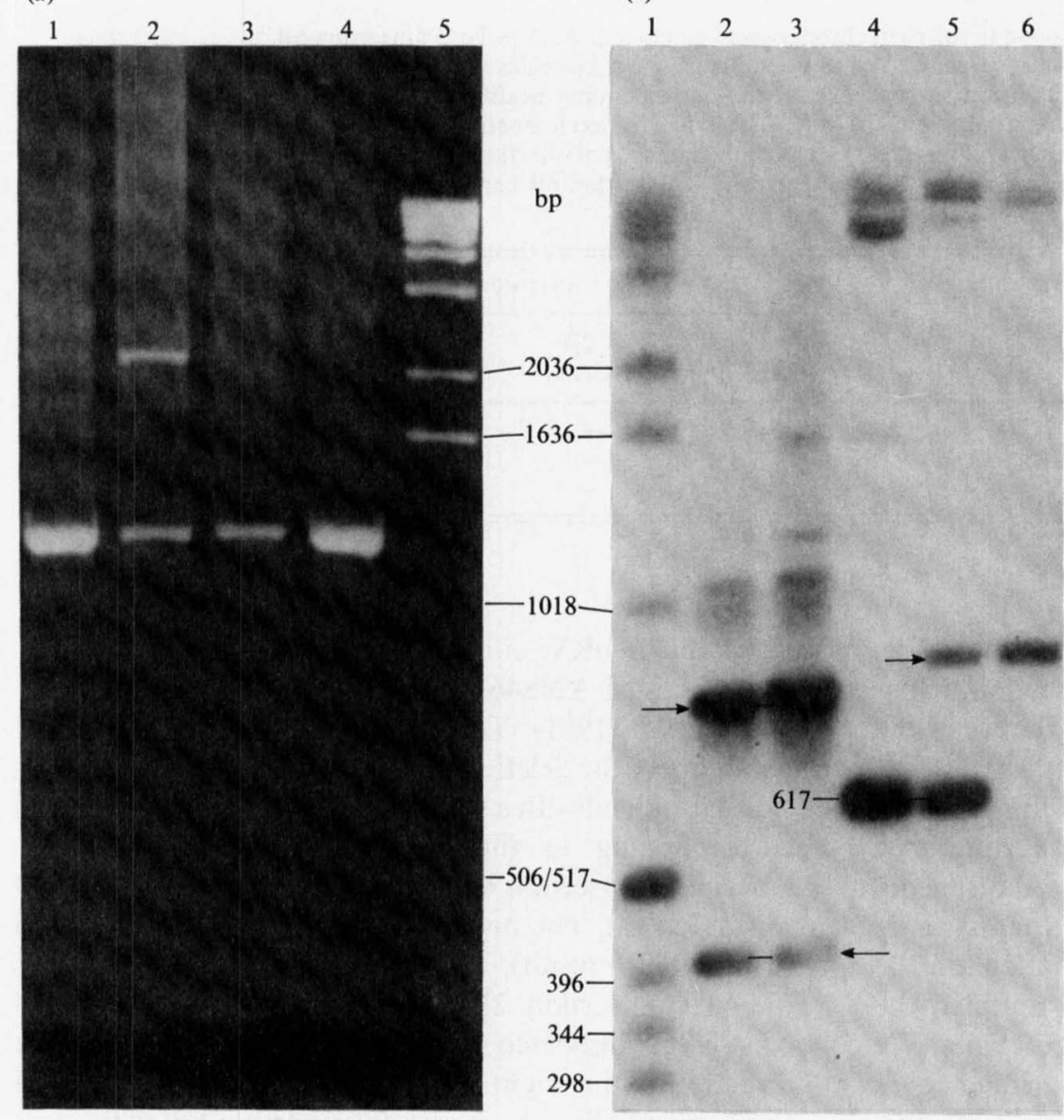

Fig. 6. PCR sizing of terminal and junction fragments of $\psi \operatorname{Tn} 554$. For $(a)$ we subjected DNA samples to PCR amplification using as primers oligonucleotide T59 and an oligonucleotide corresponding to $\mathrm{T} 6 \mathrm{~B}$, oriented towards T59 (Fig. 2 and Table 2). Samples $(10 \%)$ of the products were subjected to electrophoresis through a $1.2 \%$ agarose gel and stained with ethidium bromide. Lanes: 1 , ANS46 DNA previously treated with HindIII; 2, intact ANS46 DNA; 3, R35 DNA previously treated with HindIII; 4, intact R35 DNA; 5, 1 kb ladder. For $(b), 1 \%$ portions of two of the PCR products were digested with $\mathrm{HpaI}$, and subjected to electrophoresis as for $(a)$. HpaI plus XhoI digests of chromosomal DNA preparations were run in parallel. After blotting, the filter was hybridized with $\mathrm{Tn} 554$ probe Bl (Fig. 2). Lanes: 1, '1 kb ladder'; 2 and 3, Hpal-treated PCR product of HindIII-digested ANS46 and R35 DNA, respectively; 4-6, $\mathrm{Hpal} / \mathrm{Xhol}$ digests of ANS62, ANS46, and R35 chromosomal DNA, respectively. Sizes of pertinent marker bands are in bp; a $617 \mathrm{bp}$ band arising from an internal $\mathrm{Hpal} / \mathrm{Xhol}$ fragment of Tn554 (Murphy et al., 1985) was also used as a size marker. Relevant experimental bands are designated by arrows: namely, the $\mathrm{HpaI}$ fragments of the PCR products, which were estimated to be 820 and $410 \mathrm{bp}$; and the HapI/XhoI junction fragments of $\psi \operatorname{Tn} 554$, which were estimated to be $900 \mathrm{bp}$. were obtained by comparing HpaI digests of the PCR products with $\mathrm{XhoI} / \mathrm{HpaI}$ digests of chromosomal DNA (Fig. 6b). The difference between the appropriate PCR fragments and corresponding chromosomal fragments was $80 \mathrm{bp}$, indicating that the $X h o \mathrm{I}$ site is located this distance $( \pm 10 \mathrm{bp})$ from the pseudotransposon.

The chromosomal restriction sites near the right junction of insertion $6 \mathrm{~B}^{\prime}$ of ANS62 are a mirror image of those near the left junction of $\psi \operatorname{Tn} 554$ (as drawn in Fig. 2 ). Thus, when both regions are viewed in the same orientation relative to the chromosome (Fig. 1), the restriction patterns are essentially the same. In particular, the right junction $R s a \mathrm{I} / \mathrm{XhoI}$ fragment of insertion $6 B^{\prime}$ is $\approx 160$ bp (Fig. 2). Since the rightmost RsaI site in Tn554 is $80 \mathrm{bp}$ from the end (Murphy et al., 1987), the $X$ hol site adjacent to insertion $6 \mathrm{~B}^{\prime}$ of ANS62 (Fig. 2) must be $\approx 80 \mathrm{bp}$ beyond the transposon. These results indicate that the chromosomal sequences rightwards from the $X h o \mathrm{I}$ site flanking insertion $6 \mathrm{~B}^{\prime}$ and leftwards from the $X h o I$ site flanking $\psi \mathrm{Tn} 554$ (Fig. 2) are similar. Thus, the right boundary of $\triangle \mathrm{ANS} 46 / 62$ is located between the right end of $\psi \operatorname{Tn} 554$ (as drawn in Fig. 1) and the chromosomal $X h o$ I site, and extends no further than $\approx 80 \mathrm{bp}$ past the pseudotransposon.

\section{Discussion}

\section{General features of the mec region of ANS46 and comparison to New Jersey Mcr lineages}

The present studies have mapped all the sites for five restriction endonucleases and many of the sites for another seven over a stretch of $55 \mathrm{~kb}$ of chromosomal DNA corresponding to the mec region of the prototype Australian Mcr isolate ANS46 (Figs 1 and 2). In addition to mec, this region contains determinants for spectinomycin and MLS-resistance (in Tn554), $\mathrm{Hg}^{\mathrm{r}}, \mathrm{Tc}^{\mathrm{r}}$ (in pT181), and $\mathrm{Cd}^{\mathrm{r}}$ (in a novel element, $\psi \mathrm{Tn} 554$ ).

The mec region of the New Jersey isolate R155 differs substantially from that of ANS46. It lacks the integrated plasmid pT181, the pseudotransposon $\psi \mathrm{Tn} 554$ (with its $\mathrm{Cd}^{\mathrm{r}}$ determinant) and the $\mathrm{Hg}^{\mathrm{r}}$ locus present in ANS46. However, the homologies between the left arms of att 155 and att46, and between the right arms of att 155 
and att $\psi$ Tn554, imply that strains R155 and ANS46 have evolved from a common $\mathrm{Mc}^{\mathrm{r}}$ ancestor. Complex rearrangements in the regions flanking the attachment sites must have occurred during the divergence of the two lineages.

The relationship between the Australondon group and New Jersey Mcr isolate R35 appears to be much closer. Our initial hybridization results led us to suggest that R35 contained the equivalent of att155, but that sequences different from Tn554 were inserted in this attachment site (Tillotson et al., 1989). The present work shows that this 'insertion' constitutes more than $30 \mathrm{~kb}$ of mec region DNA, and that the att 155 right arm occurs in the wrong orientation relative to the left. It is simpler to view the mec region of R35 as a virtual copy of that of ANS46, without a Tn554 insertion in its version (att35) of att46. Also, one can view the region of R35 corresponding to the right arm of att 155 as an arm of att $\psi \mathrm{Tn} 554$. We propose that R35 and the Australondon strains share a relatively recent common ancestry, and that integration of the Tn554 insertions into the DNA of an ANS46 ancestor occurred in Australia or England after the geographical separation of the Australondon and R35 lineages.

Strain R35 was collected in a 1987 survey of two New Jersey hospitals, and was the only one of its kind among $35 \mathrm{Mc}^{r} S$. aureus isolates characterized (most being similar to strain R155) (Tillotson et al., 1989). This seemed to belie the apparent ability of Australondon strains to spread and displace other $\mathbf{M c}^{\mathrm{r}}$ strains (Pavillard et al., 1982; Cookson \& Phillips, 1988). Interestingly, a more recent (1990) survey showed that in one of these New Jersey hospitals, R35-like $\mathbf{M c}^{\mathrm{r}}$ strains now predominate, although the original New Jersey outbreak (R155-like) strains continue to predominate at the other hospital (D. T. Dubin \& W. D. Jenssen, unpublished results).

\section{The ANS46/ANS62 deletion}

The deletion of mec DNA in ANS62 was shown here to be $41 \mathrm{~kb}$ (Fig. 1), which is in accord with a recent estimate $(\approx 50 \mathrm{~kb})$ based on field inversion gel electrophoresis (Inglis et al., 1990).

The proximity of the left boundary of $\triangle \mathrm{ANS} 46 / 62$ to the right boundary of insertion $6 \mathrm{~B}$ led earlier to the suggestion that the transposon might have played a role in generating the deletion (Dubin, 1990). The present work, which demonstrates the precise coincidence of these boundaries, strengthens this idea. The fact that the right boundary of the deletion is now shown to be at or near an end of $\psi \operatorname{Tn} 544$ suggests that the pseudotransposon was also involved in the deletional event. The exact nature of this event remains to be determined.
Strain ANS62 was recovered by screening $\approx 3000$ colonies for methicillin sensitivity after treatment of ANS46 with acriflavine. The ANS46/ANS62 type of deletion is probably not a rare event, and indeed may occur even more frequently with other types of stress, for example ultraviolet irradiation (P. R. Matthews \& P. R. Stewart, unpublished observations). Similar types of deletion involving the mec region can occur upon storage, or under conditions of starvation (Matthews et al., 1990; Inglis et al., 1990). The Tn554 and $\psi \operatorname{Tn} 554$ insertions of ANS46 DNA as well as the copies of IS257 may contribute to the instability and the evolutionary variation of this region.

\section{Nature of $\psi T n 554$}

The portion of $\mathrm{Tn} 554$ to which $\psi \mathrm{Tn} 554$ shows extended sequence similarity (roughly the left half as drawn in Fig. 2 ) is that which encodes the Tn554 transposases (Murphy et al., 1985). There is good evidence that the other region of $\psi \mathrm{Tn} 554$ contains the $\mathrm{Cd}^{\mathrm{r}}$ determinant that is present in ANS46. A probe containing sequences from the cadA gene of plasmid pI524 hybridized with the $10 \mathrm{~kb} \mathrm{XbaI}$ fragment of ANS46 corresponding to coordinates 34$44 \mathrm{~kb}$ of Fig. 1 (Matthews et al., 1990). This, coupled with the present results showing that the left portion of MA14 (orientation as for Fig. 1) corresponds to an arm of att $\psi \mathrm{Tn} 554$, supports the placement of the $\mathrm{Cd}^{\mathrm{r}}$ determinant of ANS46, as shown in Fig. 1, in the EcoRV/Sall fragment of MAl4. DNA from all of the $\mathrm{Cd}^{r}$ strains listed in Table 1 hybridized to this fragment, whereas

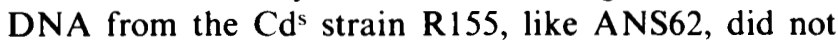
(data not shown). Ongoing sequence analysis will identify the $\mathrm{Cd}^{\mathrm{r}}$ gene of $\psi \mathrm{Tn} 554$ and will determine if reading frames corresponding to $\mathrm{Tn} 554$ transposases remain intact. This will help ascertain whether $\psi \operatorname{Tn} 554$ is a mobile element and what its evolutionary relationship to Tn554 might be.

This work was supported in part by the National Health and Medical Research Council of Australia (P.R.S.). We thank Lotus MoonMcDermott and Sheila Mazar for their technical assistance and JoAnn Humphrey and Michael Russo for their help in preparing illustrations.

\section{References}

Barry, A. L. \& ThORnSBerry, C. (1980). Susceptibility testing: diffusion test procedures. In Manual of Clinical Microbiology. 3rd edn, pp. 463-474. Edited by E. A. Lennette. Washington: American Society for Microbiology.

BeCK, W. D., Berger-BaChI, B. \& Kayser, F. H. (1986). Additional DNA in methicillin-resistant Staphylococcus aureus and molecular cloning of mec-specific DNA. Journal of Bacteriology 165, 373-378.

Berent, S. L., Mahmoudi, M., Torczynski, R. M., BragG, P. W. \& Bollon, A. P. (1985). Comparison of oligonucleotide and long DNA fragments as probes in DNA and RNA dot, Southern, Northern, colony and plaque hybridization. Biotechniques 3, 208-220. 
Chikramane, S. G., Matthews, P. R., Noble, W. C., Stewart, P. R. \& DuBIN, D. T. (1991). Tn554 inserts in methicillin-resistant Staphylococcus aureus from Australia and England: comparison with an American methicillin-resistant group. Journal of General Microbiology 137, 1303-1311.

Cookson, B. D. \& Phillips, I. (1988). Epidemic methicillin-resistant Staphylococcus aureus. Journal of Antimicrobial Chemotherapy 21 (suppl. C), 57-65.

DuBIN, D. T. (1990). Tn554 and related DNA: mapping and tracking the staphylococcal chromosome. In Molecular Biology of the Staphylococci, pp. 85-98. Edited by R. Novick. New York: VCH Publishing.

Dubin, D. T., Matthews, P. R., Chikramane, S. G. \& Stewart, P. R. (1991). Physical mapping of DNA from the mec region of an American methicillin Staphylococcus aureus lineage. Antimicrobial Agents and Chemotherapy 35, 1661-1665.

Inglis, B., Matthews, P. R. \& Stewart, P. R. (1990). Induced deletions within a cluster of resistance genes in the mec region of the chromosome of Staphylococcus aureus. Journal of General Microbiology 136, 2231-2239.

KHAN, S. A. \& Novick, P. R. (1983). Complete nucleotide sequence of pT181, a tetracycline-resistance plasmid from Staphylococcus aureus. Plasmid 10, 251-256.

laddaga, R. A., Chu, L., Misra, T. K. \& Silver, S. (1987). Nucleotide sequence and expression of the mercurial resistance operon from Staphylococcus aureus p1 528. Proceedings of the National Academy of Sciences of the United States of America 84, 5106-5110.

LYON, B. R. \& SKURRAY, R. (1987). Antimicrobial resistance of Staphylococcus aureus: genetic basis. Microbiological Reviews 51, 88134.

Matthews, P. R., Reed, K. C. \& Stewart, P. R. (1987). The cloning of chromosomal DNA associated with methicillin and other resistances in Staphylococcus aureus. Journal of General Microbiology 133, 1919-1929.

Matthews, P. R., Inglis, B. \& Stewart, P. R. (1990). Clustering of resistance genes in the mec region of the chromosome of Staphylococcus aureus. In Molecular Biology of the Staphylococci, pp. 59-83. Edited by R. Novick. New York: VCH Publishing.

MURPHY, E. (1990). Properties of the site-specific transposable element Tn554. In Molecular Biology of the Staphylococci, pp. 123-136. Edited by R. Novick. New York: VCH Publishing.

Murphy, E., Huwyler, L. \& Bastos, M. C. (1985). Transposon Tn554: complete nucleotide sequence and isolation of tranpositiondefective and antibiotic-sensitive mutants. EMBO Journal 4, 33573365 .
Murphy, E., Phillips, S., Edelman, I. \& Novick, R. P. (1981). Tn554: isolation and characterization of plasmid insertions. Plasmid 5, 292-305.

Pavillard, R., Harvey, K., Douglas, D., Hewstone, A., Andrew, J., Collopy, B., Asche, V., Carson, P., Davidson, A., Gilbert, G., SPICER, J. \& TOSOLINI, F. (1982). Epidemic of hospital-acquired infection due to methicillin-resistant Staphylococcus aureus in major Victorian hospitals. Medical Journal of Australia 1, 451-454.

Projan, S. J., Kornblum, K., Moghazek, S. L., Edelman, I., Gennaro, M. L. \& Novick, R. P. (1985). Comparative sequence and functional analysis of pT181 and pC221, cognate plasmid replicons from Staphylococcus aureus. Molecular and General Genetics $199,452-464$

SANGER, F., Nicklen, S., \& Coulson, A. R. (1977). DNA sequencing with chain-terminating inhibitors. Proceedings of the National Academy of Sciences of the United States of America 74, 5463-5467.

Skinner, S., Inglis, B., Matthews, P. R. \& Stewart, P. R. (1988). Mercury and tetracycline resistance genes and flanking repeats associated with methicillin resistance on the chromosome of Staphylococcus aureus. Molecular Microbiology 2, 289-298.

Song, M. D., WaChI, M., DoI, M., Ishino, F. \& Matsuhashi, M. (1987). Evolution of an inducible penicillin-target protein in methicillin-resistant Staphylococcus aureus by gene fusion. FEBS Letters 221, 167-171.

Thakker-Varia, S., Jenssen, W. D., Moon-McDermott, L., WeinStein, M. P. \& DuBIN, D. T. (1987). Molecular epidemiology of macrolides-lincosamides-streptogramin B resistance in Staphylococcus aureus and coagulase-negative staphylococci. Antimicrobial Agents and Chemotherapy 31, 735-743.

Tillotson, L. E., Jenssen, W. D., Moon-McDermott, L. \& Dubin, D. T. (1989). Characterization of a novel insertion of the macrolideslincosamides-streptogramin B resistance transposon Tn554 in methicillin-resistant Staphylococcus aureus and Staphylococcus epidermidis. Antimicrobial Agents and Chemotherapy 33, 541-550.

Ubukata, K., Nonoguchi, R., Matsuhashi, M., Dong Song, M. \& KonNo, M. (1989). Restriction maps of the regions coding for the methicillin and tobramycin resistances on chromosomal DNA in methicillin-resistant staphylococci. Antimicrobial Agents and Chemotherapy 33, 1624-1626.

Weiss, A. A., MurPhy, S. D. \& Silver, S. (1977). Mercury and organomercurial resistances determined by plasmids in Staphylococcus aureus. Journal of Bacteriology 132, 197-208. 